The Basic Laws of Arithmetic

Exposition of the System. By G. Frege. Translated by M. Furth. Pp. Ixiii + 143. (Berkeley and Los Angeles: University of California Press; London: Cambridge University Press, 1964.) 40s.

T $\mathrm{T}$ is scarcely surprising that Frege's two great works, I the Grundlagen der Arithmetik (1884) and the twovolumed Grundgesetze der Arithmetik (1893, 1903), made little contemporary impression. Frege's view, that mathematical propositions are truths of pure logic, ran contrary to accepted philosophical opinions of the day; his style, partly because of the severely abstract topic, was crabbed, and his symbolism idiosyncratic. Russell's almost accidental discovery of Frege's work, and his celebrated antinomy which struck away the basis of much of Frege's elaborate construction, gave due recognition to Frege as a groat pioneer in the field of mathomatical logic. Mr. Furth provides a new translation of the introductory parts of the Grundgesetze, with the appendix in which Frege somewhat pathetically announces the receipt of the Russell paradox just as his own work was completed and sets about trying to repair the damage. An introduction of some 50 pages discusses Frege's work and explains his themes, his language and symbolism, and adds a very necessary account of the way in which certain technical terms have been translated. Frege hoped to start with a small number of logieal truths and a small number of rules of inference, and thence derive all the superstructure of arithmetic and analysis. Perhaps to-day there is less interest in building the superstructure than in examining the logical foundations, and Frege's semantics and his whole philosophy of language seem more relevant to modern enquiry than his inferred consequences.

A mathematical classic has been defined as "a book which must be written but need not be read"; it may be asking too much of modern students that they should read the originals, but $\mathrm{Mr}$. Furth gives them a good opportunity of understanding why books such as Frege's had to be written.

T. A. A. Broadbent

The Application of Continued Fractions and Their Generalizations to Problems in Approximation Theory By A. N. Khovanskii. Translated by Peter Wynn. (Library of Applied Analysis and Computational Mathematics.) Pp. xii +212 . (Groningen : P. Noordhoff, Ltd., 1963.) n.p.

THIS book is written in a pleasant and easy style. It is a welcome addition to the sparse and inaccessible literature on the application of continued fractions to approximation theory. The advent of digital computer's has renewed interest in this subject as in many situations it provides a more efficient form of approximation than power series or other forms. The book provides a suitable introduction to the larger and more theoretical treatise on the subject by H. S. Wall.

The first chapter (75 pages) is introductory; it describes various notations and basic concepts: convergents and the related recurrence relations, equivalence between continued fractions and power series and their transformations, convergence and its domain, and convergence tests for various forms of continued fractions.

The second chapter ( 75 pages) derives a continued fraction expansion for the solutions of various differential equations of the Riccati type. This leads to the expansion in continued frastion form of a comprehensive list of basic mathematical functions: binomial, trigonometric, exponential, logarithmic, hypergeometric, Bessel's, gamma functions and others.

The last two chapters describe various further techniques such as the derivation of continued fractions expansions using Cesaro summation methods and the use of matrices to describe generalized recurrence relations and their convergence.

I. M. KHABAZA

\section{Determination of $\mathrm{pH}$}

Theory and Practice. By Dr. Roger G. Bates. Pp. xv+ 435. (New York and London: John Wiley and Sons, 1964.) $100 s$.

7 HIS book is a revisod and enlarged version of Electro. metric $p \mathrm{H}$ Determinations by the same author. The scope of the book has been extended to include nortinstrumental determinations of $p \mathrm{H}$ and these are full surveyed and contrasted with instrumental measurements.

The early chapters of the book are devoted to the various definitions of $p H$ scales from theorotical and practical points of view; these are extended to part. aqueous and non-aqueous systems. The treatment of the theoretical aspocts is clearly stated with concise definitions of torms, symbols and conventions in accordance with the International Union of Pure and Applied Chem. istry recommendations. A discussion of the choice and use of secondary standards is included in a chapter on $p H$ standards, while the primary standards are fulls. defined and tabulated. The performance of primary standard solutions is usefully summarized.

Various forms of electrodes used with $p \mathrm{H}$ instruments are fully discussed. These include hydrogen, quinhydront, antimony, silver/silver chloride, calomel and glass elertrodes. Understandably, the various commercial elec. trodes and types of $p \mathrm{H}$ meters reviewed are mainly of American origin.

The book is concluded with a short section on the. principles of automatic control using $p \mathrm{H}$ sensing svstems. Regrettably, a number of useful tables are lost in the general text of the book; one would have expected such tables as those denoting $p \mathbf{H}$ values of standard buffer: solutions to have been included in the appendixes. In these days of high cost books this is remarkably good value for money; it is clearly presented and readable.

R. SAWYER

\section{L'Homme Face à Son Destin}

Par Charles Léopold Mayer. Pp. 251. (Paris : Éditions Marcel Rivière et Cic., 1964.) 11.p.

$\mathrm{N}$ this little volume the reader will find the results of a philosopher's thoughts extending over a quarter of a century. It is distinguished by its lueid French logic, combined with a certain classical inevitability of argument. There are thirty-four short chapters, and their general trend can be seen as an attempt to expose the main facets of human experience, giving due weight to both sides of a question. For example, no absolute truth can be claimed. but only relative truth, and ono law to govern the universe (necessity), or failing that, the law of chance. An interesting quasi-mechanical prineiple is introduced, namely, that of "least irritability" which controls the behaviour of the living wcrld much as Maupertuis's law of least action functions in dynamics. For the author, Nature is amoral, but axiological judgments belong to human beings. It may well be, too, that natural law is a useful and necessary fiction, though no less a person than Leonardo da Vinci venerated it, and in terms of it made both artistic and technical progress.

If an estimate is to bo made of the value of a collection of meditations such as this, it is perhaps prudent to recommend it as an academic study, sinco its conclusions are significant, but not immediately applicable to the daily. round and common task. Much of it is in the style of soliloquy, very attractively expressed in the French idiom. F. I. G. RAwLINS

\section{The Thymus in Immunobiology}

Structure, Function, and Role in Disease. Edited by Robert A. Good and Ann E. Gabrielsen. Pp. xxii +778 . (New York and London: Hoeber Medical Division, Harper and Row, 1964.) 24.50 dollars.

HIS volume is based on the proceedings of the first International Symposium on the Thymus, and, with its contributions by 72 authors, collects together 